\title{
New-onset type 1 diabetes mellitus triggered by SARS-CoV-2 infection in a patient with Hashimoto thyroiditis: a case report
}

\author{
Elena Schipani, Andrea Cozzi, Giuseppe Salvatore Murgida, Valentina Francolini, Eleonora Sisti, Stefania Di Martino, \\ Francesca Dainelli, Rosa Vecchio, Elisa Grifoni, Luca Masotti \\ Internal Medicine II, San Giuseppe Hospital, Empoli (FI), Italy
}

\begin{abstract}
New-onset type 1 diabetes mellitus is an uncommon but possible complication triggered by severe acute respiratory syndrome-related coronavirus 2 infection. Metabolic inflammation supported by cytokine storm leading to pancreatic beta cells destruction is the most probable link between coronavirus disease 2019 (COVID-19) and diabetes. Here, we describe the case of a 51-year-old female suffering from Hashimoto thyroiditis, who came to our attention for new-onset polyuria-polydipsia syndrome associated with hyperglycemia after a mild form of COVID-19 recognized two months before and already recovered. Type 1 diabetes was diagnosed.
\end{abstract}

\section{Introduction}

Coronavirus disease 2019 (COVID-19) due to severe acute respiratory syndrome-related coronavirus 2 (SARS-CoV-2) infection firstly manifested in China, in the Wuhan region, in December 2019, and then quickly spread worldwide, becoming a pandemic. In August 2020, the global number of confirmed cases exceeded 20 million, and more than 750,000 deaths have occurred. The main clinical manifestation of COVID-19 is represented by a flu-like syndrome with fever, cough, myalgia, and upper airways respiratory symptoms, while the most severe one is an acute

Correspondence: Luca Masotti, Internal Medicine II, San Giuseppe Hospital, Viale Boccaccio 20, 50053 Empoli (FI), Italy.

Tel.: +39.0571.706953. E-mail: luca.masotti@tin.it

Key words: Diabetes; SARS-CoV-2; COVID-19; hyperglycemia; glutamic acid decarboxylase-65 autoantibodies.

Contributions: the authors contributed equally.

Conflict of interests: the authors declare no potential conflict of interests.

Informed consent: received.

Received for publication: 9 October 2020.

Accepted for publication: 16 November 2020.

This work is licensed under a Creative Commons Attribution NonCommercial 4.0 License (CC BY-NC 4.0).

${ }^{\circ}$ Copyright: the Author(s), 2021

Licensee PAGEPress, Italy

Italian Journal of Medicine 2021; 15:71-73

doi:10.4081/itjm.2021.1387 respiratory failure caused by interstitial pneumonia, which is mediated by the so-called cytokine storm triggered by SARS-CoV-2, and characterized by high mortality risk. ${ }^{1}$ Among other manifestations, taste and smell abnormalities (ageusia and anosmia) and gastrointestinal syndromes with vomiting and/or diarrhea are the most frequent ones. ${ }^{2}$ Although a high percentage of patients with COVID-19 is affected by type I and II diabetes mellitus, and type II diabetes is one of the main comorbidities in these patients (often with worsening of glycemic compensation), cases of new-onset type I diabetes induced by SARS-CoV-2 are anecdotal. ${ }^{2,3}$ Reported cases of acute or sub-acute thyroiditis associated with SARS-CoV-2 infection are even fewer. ${ }^{4}$

\section{Case Report}

A 51-year-old woman came to our attention in June 2020 for persistent asthenia associated with polyuriapolydipsia syndrome for about a month. In April 2020, she had tested positive for COVID-19 after contact with a COVID-19 patient, but, being asymptomatic, she had not been hospitalized and followed hygienic preventive measures at home until serological negativization occurred at the end of May 2020. She had not taken any therapy, such as antipyretic and/or antiretroviral drugs, hydroxychloroquine, steroids, or low molecular weight heparin.

She was also suffering from hypothyroidism secondary to Hashimoto's thyroiditis and was on replacement therapy with L-thyroxine.

On her arrival in the Emergency Room, she appeared alert, oriented, eupneic, apyretic, in good hemodynamic compensation, and had no neurological deficits. Blood tests showed blood glucose levels 
higher than $700 \mathrm{mg} / \mathrm{dL}$ and a slight increase in Creactive protein values. No acidosis was found on blood gas analysis. The patient was then admitted to our Internal Medicine ward. Here, blood tests showed elevated levels of anti-glutamic acid decarboxylase 65 (anti-GAD65) antibodies (2811 IU/mL, normal values $<5.00)$, C-peptide at the lower limits of normal (1.0 $\mathrm{ng} / \mathrm{mL}$, normal values $0.8-4.2 \mathrm{ng} / \mathrm{mL}$ ), normal pancreatic elastase, and a glycosylated hemoglobin value of $17.6 \%$ (normal values $<5.6 \%$ ) (169 $\mathrm{mmol} / \mathrm{mol}$, normal values $<38 \mathrm{mmol} / \mathrm{mol}$ ). The antiSARS-CoV-2 antibody titer was $127.1 \mathrm{AU} / \mathrm{mL}$ (normal values $<10 \mathrm{AU} / \mathrm{mL}$ ) for immunoglobulin (Ig)G, and 5.5 AU/mL (normal values $<10 \mathrm{AU} / \mathrm{mL}$ ) for IgM. Screening for celiac disease was negative. Blood cell count, coagulation, renal and hepatic function tests, and electrolytes levels were normal. An abdomen magnetic resonance imaging examination showed no abnormal findings. The patient was initially treated with intravenous insulin infusion and subsequently with subcutaneous insulin according to a basal-bolus regimen with good glycemic values compensation.

\section{Discussion and Conclusions}

Diabetes mellitus represents, together with arterial hypertension, the main co-morbidity in patients with SARS-CoV-2 infection and is associated with worse outcomes. ${ }^{5}$ The new onset of type I diabetes in patients with SARS-CoV-2 infection and severe forms of diabetic ketoacidosis or hyperosmolarity requiring high doses of insulin has already been reported in anecdotal cases, leading a group of researchers to propose an international multicenter registry to verify the real impact in daily clinical practice. ${ }^{3}$ The mechanism by which SARS-CoV-2 infection could trigger type I diabetes has not been clarified yet. In diabetic patients, a metabolic inflammation has been hypothesized, predisposing to an increased cytokine release when an infection occurs. The so-called cytokine storm induced by SARS-CoV-2 has been extensively described and seems to be involved in multi-organ failure occurring in severe forms of COVID-19. ${ }^{5,6}$ The endocrine link in SARS-CoV-2 infection might be represented by the interaction between a virus surface glycoprotein and angiotensinconverting enzyme 2 (ACE-2), which acts as a receptor for this glycoprotein and is highly expressed by pancreatic cells. ACE- 2 has a protective effect on inflammatory mechanisms. The binding of SARSCoV-2 to ACE-2 reduces the expression of ACE-2, triggering the damage of pancreatic beta cells and consequently reducing insulin release..$^{5}$ Another interesting hypothesis is that human dipeptidyl peptidase-4 (DDP-4) could act as a receptor and interact with the S1 domain of the SARS-CoV-2 glycoprotein, allowing the virus to enter the pancreatic cells, thus further explaining the relationship between SARS-CoV-2 and new-onset type 1 diabetes mellitus. ${ }^{7}$ The consequent hypothesis that using DDP-4 inhibitors, which are today a standard treatment for type 2 diabetes mellitus, could provide therapeutic opportunities against SARS-CoV-2 infection is even more fascinating. ${ }^{7}$

To date, reports of thyroiditis induced by SARSCoV-2 infection are infrequent, and the mechanism of thyroid damage mediated by inflammation and the abnormal response of the immune system remains the most likely one., ${ }^{4,8}$

Our case involves a woman with Hashimoto's thyroiditis, who acutely developed type 1 diabetes after SARS-CoV-2 infection. The high levels of antiGAD65 antibodies and low levels of C-peptide confirmed the hypothesis of type 1 diabetes. We believe that in this patient, already suffering from an autoimmune disease such as Hashimoto's thyroiditis, an abnormal immune and inflammatory response triggered by SARS-CoV-2 infection may have occurred, leading to an autoimmune insulitis with the destruction of pancreatic beta cells and new onset of type I diabetes. Other similar reports have been recently published. ${ }^{9-11}$

In conclusion, the cytokine storm characterizing the inflammatory response triggered by SARS-CoV2 can lead to an abnormal immune reaction against pancreatic beta cells, causing the onset of type 1 diabetes mellitus. Therefore, early monitoring and follow-up of COVID-19 patients with thorough metabolic control of paramount importance to intercept the possible occurrence of this complication.

\section{References}

1. Baj J, Karakuła-Juchnowicz H, Teresiński G, et al. COVID-19: specific and non-specific clinical manifestations and symptoms: the current state of knowledge. J Clin Med 2020;9:1753.

2. Azar WS, Njeim R, Fares AH, et al. COVID-19 and diabetes mellitus: how one pandemic worsens the other [published online ahead of print, 2020 Aug 2]. Rev Endocr Metab Disord 2020;1-13.

3. Rubino F, Amiel SA, Zimmet P, et al. New-onset diabetes in COVID-19 [published online ahead of print, 2020 Jun 12]. N Engl J Med 2020;10.1056/NEJMc2018688.

4. Ruggeri RM, Campennì A, Siracusa M, et al. Subacute thyroiditis in a patient infected with SARS-COV-2: an endocrine complication linked to the COVID-19 pandemic [published online ahead of print, $2020 \mathrm{Jul} 16$ ]. Hormones (Athens) 2020;1-3.

5. Bornstein SR, Rubino F, Khunti K, et al. Practical recommendations for the management of diabetes in patients with COVID-19. Lancet Diabetes Endocrinol 2020;8:546-50. 
6. Ye Q, Wang B, Mao J. The pathogenesis and treatment of the 'Cytokine Storm' in COVID-19. J Infect 2020;80:607-13.

7. Marazuela M, Giustina A, Puig-Domingo M. Endocrine and metabolic aspects of the COVID-19 pandemic [published online ahead of print, 2020 Jul 9]. Rev Endocr Metab Disord 2020;1-13.

8. Bellastella G, Maiorino MI, Esposito K. Endocrine complications of COVID-19: what happens to the thyroid and adrenal glands?. J Endocrinol Invest 2020;43:1169-70.
9. Heaney AI, Griffin GD, Simon EL. Newly diagnosed diabetes and diabetic ketoacidosis precipitated by COVID19 infection [published online ahead of print, 2020 Jun 6]. Am J Emerg Med 2020;S0735-6757(20)30488-5.

10. Marchand L, Pecquet M, Luyton C. Type 1 diabetes onset triggered by COVID-19 [published online ahead of print, 2020 Jul 11]. Acta Diabetol 2020;1-2.

11. Chee YJ, Ng SJH, Yeoh E. Diabetic ketoacidosis precipitated by COVID-19 in a patient with newly diagnosed diabetes mellitus. Diabetes Res Clin Pract 2020;164:108166. 